\title{
Exploring power and participation through informal livestock knowledge networks
}

\author{
A.J. Tasker* \\ University of Sussex, Falmer, Brighton, BN1 9RH, UK
}

A R T I C L E IN F O

\section{Keywords:}

Knowledge

Network

Power

Livestock

Development

\begin{abstract}
A B S T R A C T
Participatory epidemiology programmes aim to collect data by engaging local communities in knowledge sharing around livestock health. Critics of participatory approaches often cite the extractive nature of data collection and unequal power relations between researcher and researched as at odds with the original vision of participatory programming. This paper starts from the position that rural livestock owners are situated within multiple overlapping webs of relationships through which they exchange disease information and access resources. Participatory programmes are suggested as weaving new threads into these wider networks in a process that may be accepted or rejected by indigenous actors. Qualitative interviews were used to gather empirical data on the exchange of information around livestock health knowledge through indigenous relationships and a Participatory Disease Surveillance (PDS) programme within a Gabra pastoralist community in Northern Kenya. Subsequent analysis identified four pathway typologies; this paper provides a qualitative comparative analysis of each to explore the nature of participation within the study population. The paper concludes that social science approaches have a key role to play in understanding how relationships within and between indigenous and development actors can influence participation in development projects.
\end{abstract}

\section{Introduction}

"Phone credit is better medicine for the camel than blood tests"

Yarra, Gabra elder and herder

In this sentence Yarra highlighted a common blind spot of participatory approaches for engaging indigenous livestock knowledge. Like rural communities across the globe, the Gabra draw on complex webs of relationships to access a diverse range of livestock health knowledge and resources. Development programmes can be seen as new strands woven into existing webs of indigenous knowledge but few studies have directly addressed the dynamics of inclusion and exclusion of these external relationships. This study suggests that understanding these processes may be of fundamental importance in shaping the nature and outcomes of participatory programming. This paper explores how indigenous livestock health knowledge exchanges and a Participatory Disease Surveillance (PDS) project intersect to understand how interactions may shape the nature and flows of livestock health knowledge in the field. Qualitative data on livestock health knowledge exchange was collected and analysed to map the social and cultural landscapes in which the PDS programme was situated.

\section{Participatory dislocation}

Participatory programmes aim to redress power imbalances between indigenous and external actors. The value of effective participation to development programming has been demonstrated in successes across the globe from community-led animal health interventions (Admassu, 2002) to rinderpest eradication (Catley and Leyland, 2001). This Article Collection focuses on a specific participatory approach Participatory Epidemiology (PE) - that "has been praised for enabling people with no or low levels of formal education to communicate their knowledge in a way that researchers can relate to, record and analyse" (Fischer and Chenais, 2019, p.34). This definition places the burden of legibility on 'uneducated' indigenous populations to enable researchers to more easily do their work, a position that potentially reinforces the extractive nature of some participatory approaches (Cleaver, 1999). Differences between meaningful participation and meaningless involvement continue to be debated by academics (Arnstein, 1969; Pretty et al., 1995; Robinson, 2002; Stewart and Sinclair, 2007) for overlooking the normative aspects of power (e.g. Cleaver, 1999; Mohan and Stokke, 2000; Mansuri and Rao, 2004). Misunderstanding indigenous power can reinforce local power asymmetries (Cooke and Kothari, 2001; Mosse, 2001; Corbridge and Kumar, 2002) stemming in part from

\footnotetext{
* Correspondence to. Present Address: Department of Anthropology, University College London, 14 Taviton St, Kings Cross, London, WC1H 0BW, UK.

E-mail address: a.tasker@ucl.ac.uk.
} 
homogenisations of indigenous populations (Cooke and Kothari, 2001).

\subsection{Conceptual foundations}

This study adopts the definition of PE given by Catley et al. (2012) as the 'systematic use of participatory approaches and methods to improve understanding of diseases and options for animal disease control' (Ibid., p.151). This study will explore two keys aspects of this position; firstly the implicit transfer of knowledge occurring through participatory approaches to increase understanding, and secondly how networks of individuals shape transfers of knowledge. Networks of collective relationships can be powerful objects (Castells, 2011) that can enable or deny non-members' access to knowledge or resources. Networks can enable the capture of programme resources by elites, in direct opposition to participatory ideals (Cooke and Kothari, 2001; Mosse, 2001; Corbridge and Kumar, 2002); applications of power such as these are complex objects to study (Meusburger et al., 2016). Drawing on the work of Levy and Egan (1998); Lukes (2012), and Kolleck (2013) this study employs three theoretical dimensions of power to aid analyses: the relational (between actors), structural (derived from the position of actors within social units), and discursive (rooted in the nature of actor exchanges).

This relational approach to power is highly appropriate for exploring how livestock health knowledge flows through networks of connections as network approaches are a well-established conceptual tools for researching rural agricultural communities (Sligo et al., 2005; Sligo and Massey, 2007). Network literature helps to expose the reality of pastoralist livelihoods in which networks may follow spatial, social, kinship, activity, and migratory patterns whilst simultaneously being influenced by geography, infrastructure, and technology (Abler, 1974; Hillis, 1998). Mainstream network approaches such as Social Network Analysis derive their analytical power from an ability to quantitatively identify structures and positions within wider networks this study choses to employ a more descriptive qualitative approach that recognises 'qualitative methods can be a powerful means for discerning themes in the social network data that may not emerge through using quantitative methods of data collection and analysis (Hersberger, 2003, p.4). Qualitative network approaches enable researchers to explore complex features of interpersonal relationships that may shape knowledge exchange such as trust (Kolleck and Bormann, 2014) and belonging (Rosen et al., 2011). This study employed network maps as analytical tools mapping knowledge transfers, and discursive objects to stimulate data collection (Bellotti, 2016). The constructed networks were reviewed in conjunction with qualitative interview data to identify and explore the type, nature, and extent of livestock knowledge exchanges occurring, enabling the tracing of pathways of knowledge typologies passing throughout the network. The three core research questions of the study were firstly, to identify pathways of livestock health knowledge transfer. Secondly, what knowledge was being transferred within these pathways, and lastly, what shapes actors' decisions to use specific pathways.

\section{Study site and population}

Originally nomadic, the Gabra pastoralist community has increasingly settled in the East African region (Watson and Binsbergen, 2008). This study focuses on the settlement of North Horr $\left(3.3206{ }^{\circ} \mathrm{N}, 37.0695\right.$ $\left.{ }^{\circ} \mathrm{E}\right), 200 \mathrm{~km}$ north west of Marsabit town. North Horr is home to a mixed population of settled and transitory Gabra who combine sedentary and transhumant livelihoods, making accurate estimates of the population difficult. Mixed-form pastoralism is considered by local communities to be highly sustainable for the region as traditional rural livelihoods seen elsewhere in Kenya are rarely appropriate; only 3\% of the available land can be considered suitable for farming (ALRMP, 2008). The Gabra are traditionally a camel-keeping pastoralist society, however in recent years herds have been expanded to include sheep, goats, donkeys, and rarely cattle (Ganya et al., 2004). Regardless of species, livestock remain economically (Robinson and Berkes, 2010) and socio-culturally (Tablino, 1999) central to the Gabra way of life which has led to the development of unique cultural and social institutions governing relationships between herders and livestock. These social structures are common to many pastoralist communities and lead to deep social repositories of knowledge around livestock health and disease (Waller and Homewood, 2017). Livestock health knowledge is accessed at multiple levels; between individuals, through age sets, gosa ${ }^{1}$, luba and gada ${ }^{2}$ systems, and via elders and Chilres (cultural livestock experts) who act as repositories of indigenous knowledge. These systems co-exist as pathways for the access, dissemination, and discussion of a wide range of knowledge; in recent years many households have drawn on community knowledge to diversify herds or move away from traditional livelihoods (Watson and Binsbergen, 2008) into wholesale and retail trade, waged employment, and farming (Little et al., 2001). In some cases pastoralists have abandoned mobile livelihoods altogether and the resulting sedenterisation has had profound effects on social and cultural structures (Witsenburg and Roba, 2004; Diocese of Marsabit, 2012).

Conditions remain difficult for the pastoralist inhabitants of the region. The area around North Horr has experienced worsening droughts over the last fifty years to the current average of $400-800$ mm rainfall per year (Dabasso and Okomoli, 2015). The harsh climate and marginalisation of the region from the rest of Kenya have attracted the attention of development groups for decades, spurred on by the major droughts of the 1970s and 1980s. At this time Marsabit District saw an influx of relief and development agencies (Fratkin and Roth, 2005) bringing interventions that faced significant challenges to implementation (Sandford, 1983), resulting in limited successes (Hogg, 1987; Baxter, 1991; Anderson and Broch-Due, 1999). The most recent publicly available figures suggested that in 2005 there were more than one hundred and fifty Non-Governmental Organisations (NGOs) registered in Marsabit, of which fewer than $15 \%$ could be considered active (Muriungi, 2012). Along with governmental agencies and religious groups, NGOs provide Gabra pastoralists access to scarce resources such as financial support and technical assistance. North Horr has been a site for international development since the 19th century; over time many of the connections between the external agencies and communities have developed robust foundations and unique power dynamics (Mosse, 2001).

\subsection{Participatory disease surveillance and the gabra}

The central role of livestock for Gabra culture and survival has led to livestock health becoming a core theme in development programming for the region. In 2013 a Participatory Disease Surveillance (PDS) programme was implemented by Veterinaires Sans Frontieres Germany (VSF-G), funded through the Enhancing Resilience in Communities Affected by Drought in Marsabit and Tana River Counties (REACT) programme in collaboration with OXFAM, ACTED, and Concern Worldwide. PDS approaches are a form of PE focused on disease surveillance through active engagement of indigenous knowledge and oral communication networks (Mariner et al., 2011), in this case through the training and employment of a Community Disease Reporter (CDR). PDS programmes typically link researchers with local livestock herders and key selected informants to evaluate their perceptions of disease through interviews, visualisations, and discussions that employ

\footnotetext{
${ }^{1}$ Gabra society is divided into five Gosa (phatries), the Algaanna, Gaara, Galbo, Odoola, and Shaarbana that provide close non-family contacts with whom the Gabra often organise work and exchange knowledge.

${ }^{2}$ Gada refers to the traditional social system of the Oromo people, of which $l u b a$ is a series of classes. For more see authors such as Hallpike (1976), or Tablino (1999).
} 


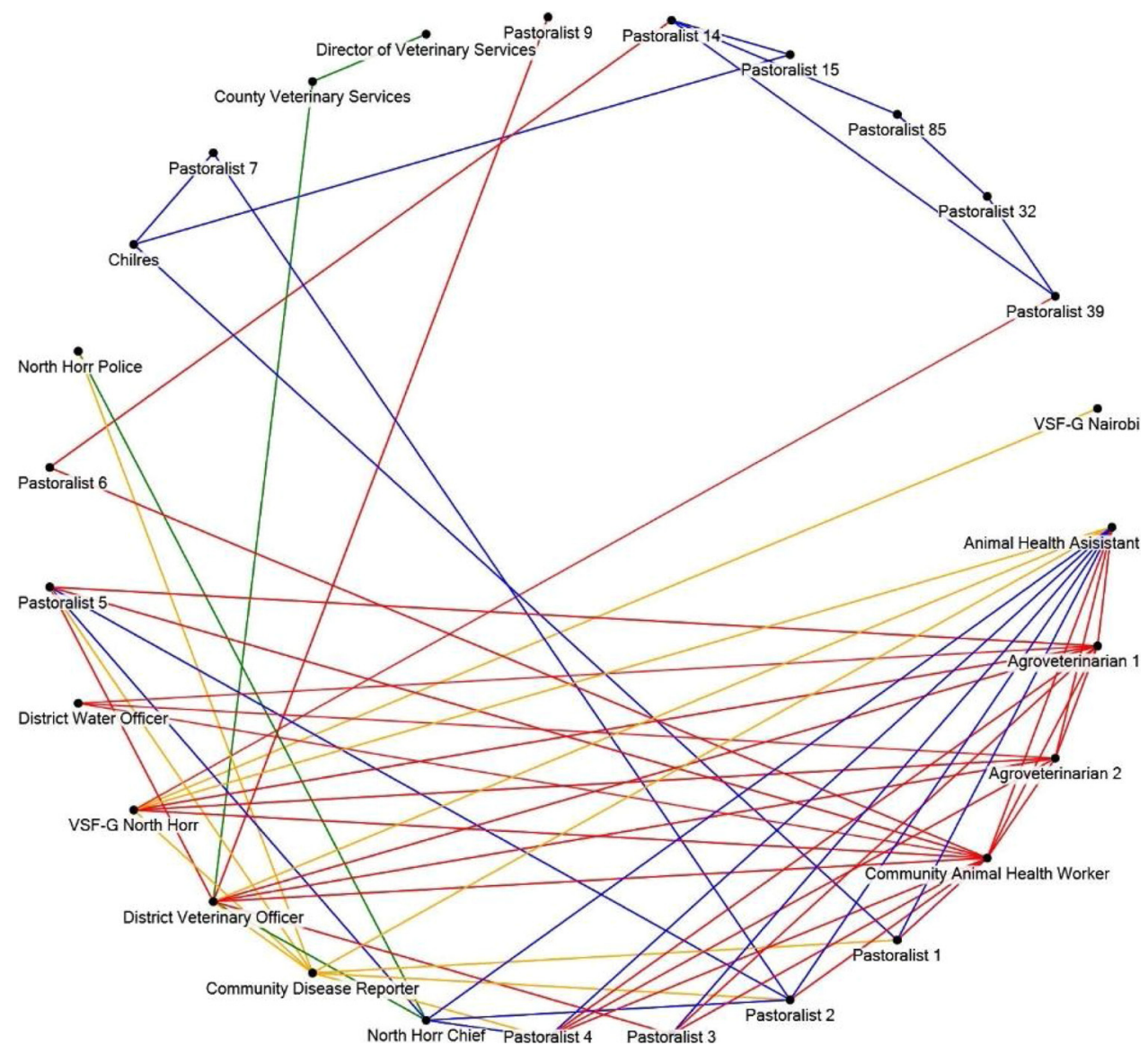

Fig. 1. Livestock health knowledge relationships.

participatory tools such as ranking, calendars, and scoring (Ameri et al., 2009; Allepuz et al., 2017). In North Horr the training for the CDRs focused on 'notifiable diseases and those of economic importance' (Kimondiu et al., 2016) as defined by the Government of Kenya, transferring this information to government District and County Veterinary Officers (DVO and CVO). The programme was specifically designed to strengthen links between community livestock keepers and government service providers through collaborative investigations and treatment planning. This study suggests the North Horr PDS programme was an attempt by NGOs to construct new relationships via CDR gatekeepers to pathways of indigenous knowledge exchange. The study of this type of programme requires close attention to the role and nature of knowledge transfer relationships, and a nuanced understanding of the contexts in which these networks operate.

\section{Materials and methods}

Understanding knowledge exchange between differing cultures can be a highly complex task, highly influenced by values and contextual factors (Gamson and Modigliani, 1987; Druckman, 2001a, b; Barker, 2005; Shen and Edwards, 2005). This study employed qualitative interviews to gather details on the nature and content of knowledge exchanges, and used this data to identify typologies of knowledge transfer and build pathways of connected exchanges. Follow-up interviews explored barriers and access to these pathways. Data were gathered from June to August 2016 as part of a wider doctoral study of co-created knowledge between Gabra and development actors, a summary of which is contained in Appendix A. The following section provides details of the methods and populations involved in each approach.

\subsection{Respondent selection}

Starting with the Community Disease Reporter, rolling recruitment was employed to identify respondents until no new contacts were being added to the existing pool of respondents. 27 respondents were recruited, 21 defined themselves as Gabra, 6 as non-Gabra. The primary livelihoods of Gabra respondents were 14 herders, 4 technical services, 2 governmental, and 1 NGO employee. Non-Gabra actors included 4 government employees and 2 NGO actors. 122 connections were recorded between the 27 actors, collated in Microsoft Excel, analysed and visualised using the open-source software Gephi (Bastian et al., 2009) and displayed in this paper using NodeXL (Smith et al., 2010).

\subsection{Qualitative interviews}

All respondents were interviewed to identify basic demographic characteristics (ethnicity, livelihood, gender) and livestock health knowledge shared in mapped exchanges. 15 interviewees were selected for further in-depth interviewing by researcher-led identification and key informant suggestion. These 15 interviews explored the respondent's awareness and access to alternative pathways of livestock health knowledge. Interviews were conducted in English or Oromo as chosen by the respondent; trained local research assistants provided translation. Translation in qualitative research can be highly problematic (Alcoff, 1991; Back and Solomos, 1993; Wilkinson and Kitzinger, 1996; Edwards, 1998; Birbili, 2000); to address many of these difficulties the study employed three primary translators (one younger male, one older male, and one younger female) to overcome cultural or hierarchical barriers. Translators were regularly asked to cross-translate to highlight any key differences in interpretations.

The interview data was recorded electronically and in field journals, 


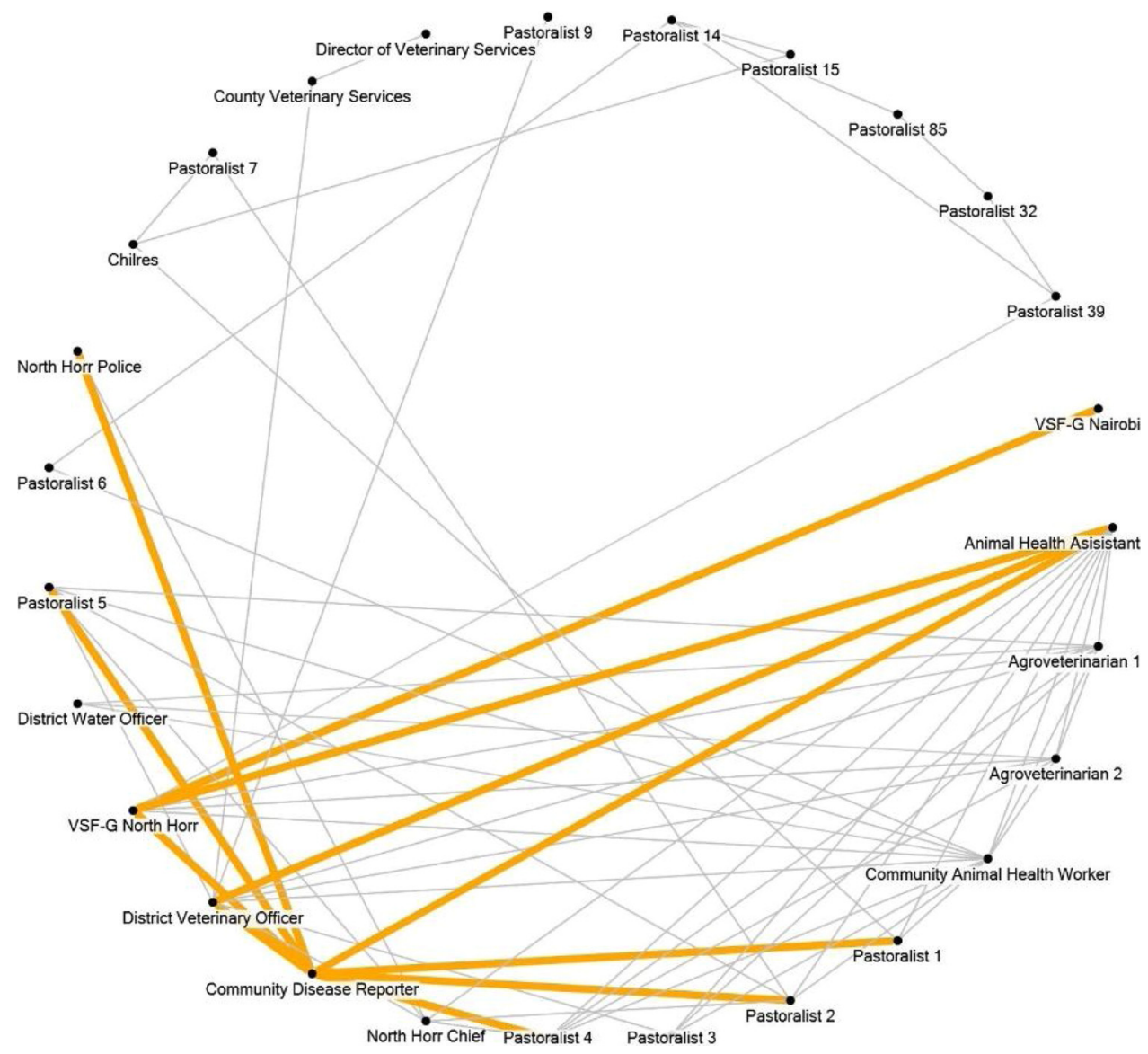

Fig. 2. PDS pathway.

and analysed in NVivo using a Thematic Analysis approach (AttrideStirling, 2001). This data was then used to identify key discourses around pathways of knowledge sharing, and to develop relationship maps of pathways of livestock health knowledge typologies. These maps were used as a interview tool (described above), and interpreted using a qualitative structural analysis framework (Herz et al., 2014) to add depth to the interview data.

\section{Results}

Relationship data was used to map connections between all respondents as shown in Fig. 1. The interview data were reviewed to identify and trace four different typologies of livestock health knowledge transfer occurring within pathways; these pathways were named after the typologies; PDS, traditional, local, and political, and are presented in Figs. 2-5. An overview map of each follows the full diagram.

\subsection{PDS pathway}

The PDS pathway contained 22 relationships between 10 actors, including the Community Disease Reporter (CDR), the District Veterinary Officer (DVO), Animal Health Assistant (AHA), County Veterinary Services (CVS), and field- and Nairobi-level representatives of VSF-G. The pathway also contained the local chief, representatives of the local police, and four local herders who had used the programme in the past. The four herders often described their contact with the PDS programme in transactional terms, with little perception of collaborative involvement: "we pass on the information because it may be good for my animals and for the community" (Pastoralist 5). The passive "passing on' of information is echoed in debates around participation and local epidemiology (LE) as described earlier by Fischer and Chenais (2019) who suggest 'the term Participatory Epidemiology $(P E)$ in future is reserved for research that commits to local participation beyond only data collection, and that the use of participatory tools to extract data about local situations is renamed as' local epidemiology' (LE)' (ibid., p.34). The perception of local herders of PDS exchanges as information provision rather than knowledge exchange differed from the discursive to-and-fro exchanges observed between pastoralists in other pathways, including by the four respondents. When pressed as to why they engaged with the CDR and PDS, the most common response was that the CDR was seen as a gatekeeper to NGO and governmental resources and a way to the ear of the DVO who could enable access to wider national markets: "in the past VSF have provided many good things, they have medicines and can help us sell animals" (pastoralist 2). Both disease treatments and market access were not always within the powers of the CDR, yet herders expressed the desire to cultivate and maintain a diverse portfolio of connections despite the costs of doing so (McFadyen and Cannella, 2004). The herders' choice to invest in these 'weak tie' relationships (Granovetter, 1983) outside of their immediate community is less surprising when considering literature on the use of social networks to mitigate uncertainty (Koppenjan et al., 2004) and risk through community resource management (Cronk et al., 2019).

Interviews with NGO and government actors suggested that the PDS worked well for pastoralist communities, supported by triangulated analyses of grey literature and anecdotal reports gathered in the field. The most common suggestion as to why the PDS scheme was popular related to the ready and observable treatments offered by government contacts in return for reporting: "they like what we offer, they can see it is good and they want us to do it" (AHA). Summary reviews record the programme as popular within communities (see, for example, Kimondiu et al., 2016) however the same publication also questioned the nature of participation within the project. Documenting routine reports by 


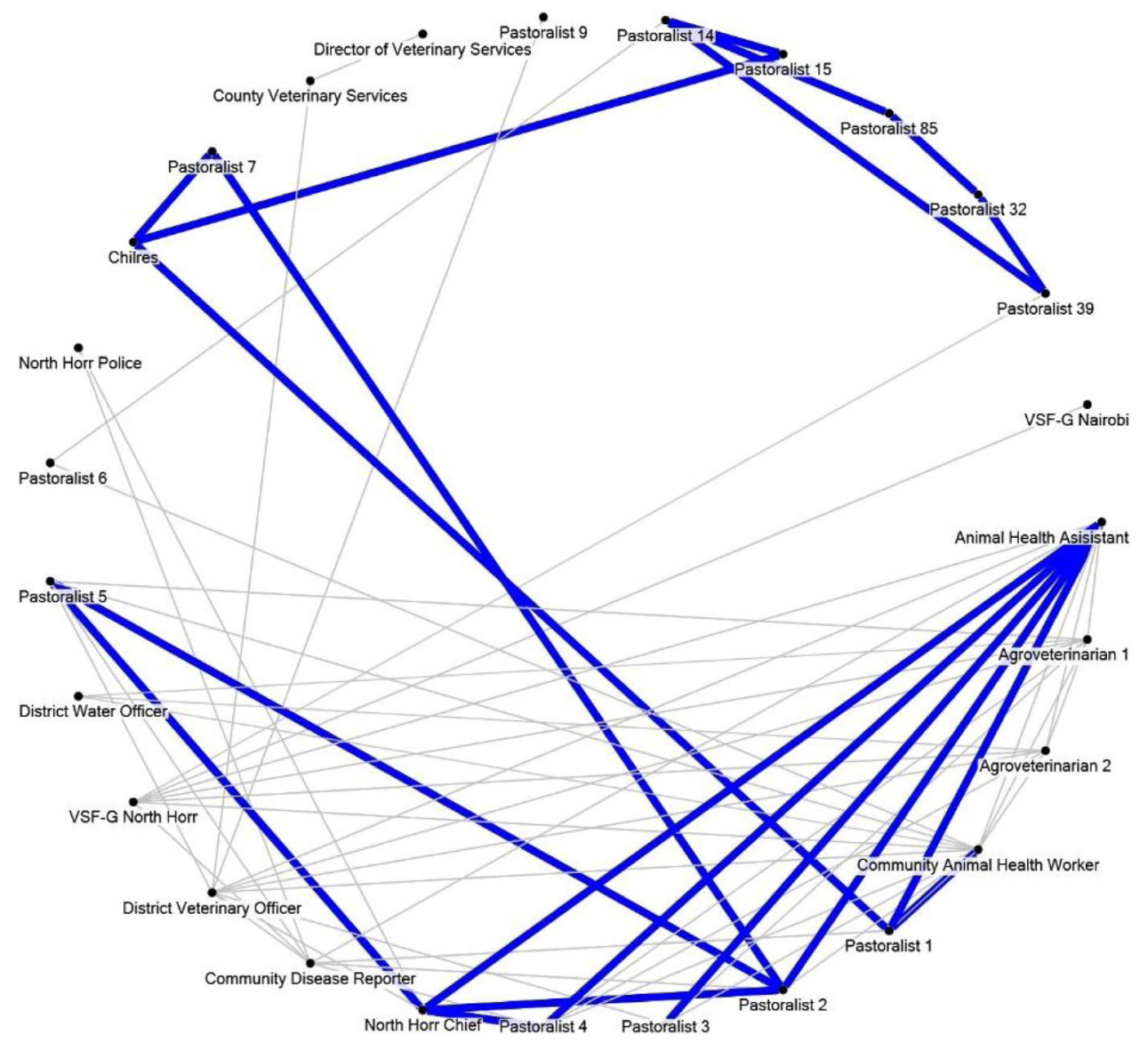

Fig. 3. Traditional pathway.

VOs, the review suggested the benefits of the PDS were an "improved awareness by livestock keepers on disease control and more effective conventional veterinary practices" and "participatory approaches gives (sic.) livestock keepers an opportunity to share and explain ethnoveterinary practices with veterinary officers which leads to decrease in ineffective or detrimental practices and maintains effective ones with clear guidance by veterinary officer" (Kimondiu et al., 2016). The use of terms such as 'ineffective' and 'detrimental' suggest a belief in the clear superiority of state animal health services, positioning the PDS programme towards Fischer and Chenais' local, not participatory epidemiology.

\subsection{Traditional pathway}

The traditional pathway highlighted a locally constructed and curated repository of livestock health knowledge. The pathway contained 37 relationships between 15 actors, typified by broadly open and accessible indigenous knowledge stocks exchanged between herders, the Chilres, and the AHA (also a Gabra herder). Closer examination of the Chilres and AHA in particular provide useful insights into the nature of communally-held livestock health knowledge.

Three of the eleven herders within this pathway suggested the Chilres as a source of livestock disease knowledge. The remaining eight suggested they saw the Chilres not as holding privileged knowledge, but as more connected to local knowledge around animal health than other members of the community. Whilst a common interpretation of Chilres is 'traditional healer', this study found this to be somewhat of a mistranslation; rather than protecting and promoting traditional approaches, pastoralists described Chilres as collators of information on livestock health including contemporary treatments and methodologies. Chilres were suggested as key people for advising on treatments and directing individuals to seek help from others, yet not all actors listed them as a personal contact in the mapping exercise; the primary reason given was pragmatically either they did not know one, or there was not one within easy reach.

In this case study the Chilres was found to have a close relationship with the AHA, demonstrated through frequent exchanges across a wide range of topics. The AHA was both a Gabra herder and government actor, capable of bridging cultural and hierarchical barriers through the use of social capital. This capital was acquired as a livestock-owning male Gabra, technological literacy, a government role, and perceived academic ability which permitted privileged entry into other pathways. When discussing connections between indigenous herders and government actors, local livestock owners cited the reciprocity and two-way nature of relationships as a key difference between the AHA and other actors such as the DVO and NGO. In these cases the DVO was seen to provide treatment directly, the NGO was able to exert pressure on the DVO to attend (partly by facilitating transport and costs), however the AHA was someone whom one informed of symptoms and who advised on treatments or further sources of knowledge - not dissimilar to the Chilres.

The intertwining of identities between the Chilres and AHA, and the reciprocity of exchange between the AHA, Chilres and herders sets the traditional knowledge sub-network apart from the other three. Access to shared knowledge repositories informed individual decisions, membership was gained through active engagement and feeding back experiences and outcomes into the collective knowledge repository. This included the results of experimental and innovative approaches, or anecdotes from non-Gabra herders elsewhere. Examples were given of Boran, Turkana and Samburu treatments for Rinderpest and Foot and Mouth disease (FMD) that had been gathered by unknown contacts elsewhere; these examples were not used as indigenous gold standards but informed the decisions of individual herders around treatments and 


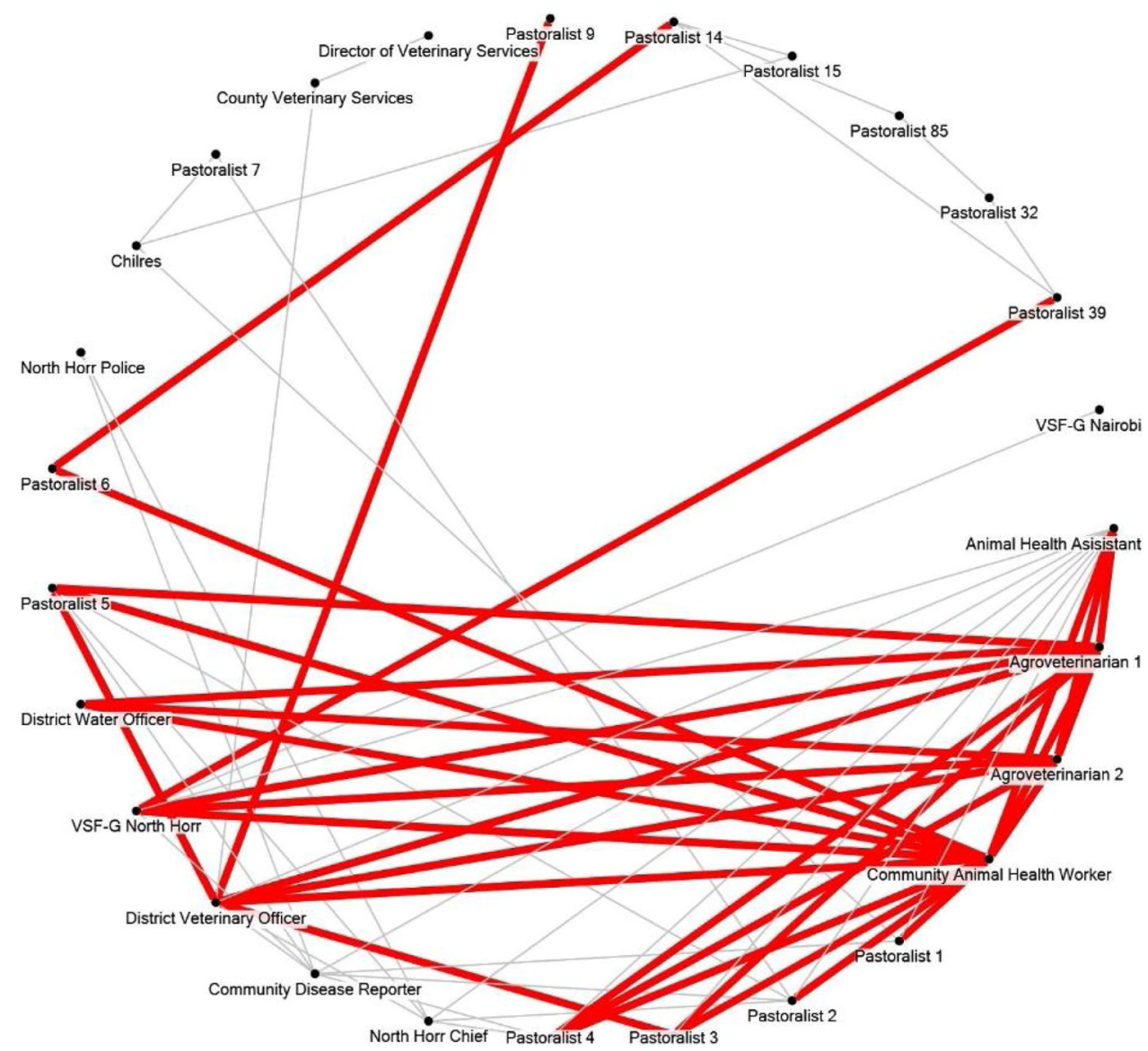

Fig. 4. Local pathway.

strategies. Fundamentally the traditional pathway demonstrated a fertile dynamic between action at an individual level, and societal- and cultural-level debate and knowledge sharing (to varying degrees).

\subsection{Local pathway}

The previous two pathways highlight the differences between the NGO-led PDS programme and indigenous forms of knowledge exchanges around livestock health. North Horr also contained multiple private sector actors engaged in animal health and disease work such as Community Animal Health Workers (CAHW) and Agroveterinarians (AV). These individuals had relationships that enabled them to draw on knowledge bases from outside the community in ways not seen in the PDS or traditional pathways. This local pathway contained 16 actors connected by 55 relationships; a key difference between the local and traditional networks was that in the traditional pathway knowledge was described as being communally held, whereas in the local pathway individuals maintained and traded knowledge independently. Within the local network the CAHW and AVs provide useful case studies to understand how actors are able to occupy niche positions within the Gabra community by bridging state, private, and community groups in a variety of ways.

CAHWs were a common feature of NGO and government extension work across East Africa, acting as treatment providers and access points for wider animal services in remote areas (Allport et al., 2005). Initially developed in India (Hadrill, 1989), Afghanistan (Leyland, 1992), and Africa (Maranga, 1992; Leyland, 1996), early CAHWs based much of their practice on participatory enquiry and collaboration with livestock keepers. When combined with increasing interest by the international community in 'ethnoveterinary knowledge' (Mathias-Mundy and McCorkle, 1989) CAHWs were positioned to act as interlocutors between state veterinary services and silos of livestock knowledge in remote communities. This service model, driven by local demand has provided a unique situation enabling almost complete privatisation of veterinary services in some remote areas (de Haan and Bekure, 1991; Holden, 1997). In some cases this position has led to mistrust or opposition from formally qualified veterinarians (Mugunieri et al., 2004), often forcing CAHWs to rely on the support of NGOs rather than existing infrastructure (Sikana et al., 1992). In 2011 the Government of Kenya removed the statutory recognition of CAHWs at the behest of professional veterinarians, for North Horr this resulted in ex-CAHWs still informally practicing and continuing to command local respect and the privileges of their previous position, maintained in part by enduring links with other animal health professionals. There was only one exCAHW present at the time of data collection, providing informal advice to a variety of community members. In many cases the CAHW would advise medications or procedures that could be obtained through local AVs or via contacts in Nairobi or across the border in Ethiopia, it was unclear if the CAWH received any financial recompense from these exchanges. The historic relationships between the CAHW and government agricultural staff meant that local herders continued to associate the CAHW with formal animal health 'expertise' acquired as part of the state system, "he (the CAHW) knows the animals and the government well, he has many friends and people who he knows and works with. He is a good man for North Horr as they (the government) will know us and our problems. He may not have the same vehicle as before, but he is still a powerful person for us and for them (government)" (pastoralist 4).

The value placed by the Gabra on experience and resource access was seen in community relationship with the AVs. AVs operated private shops supplying medicines, supplements, and feed stuffs to livestock owners; spaces in which herders would ask for advice relating to nonresponsive disease cases or troublesome conditions. Formally 


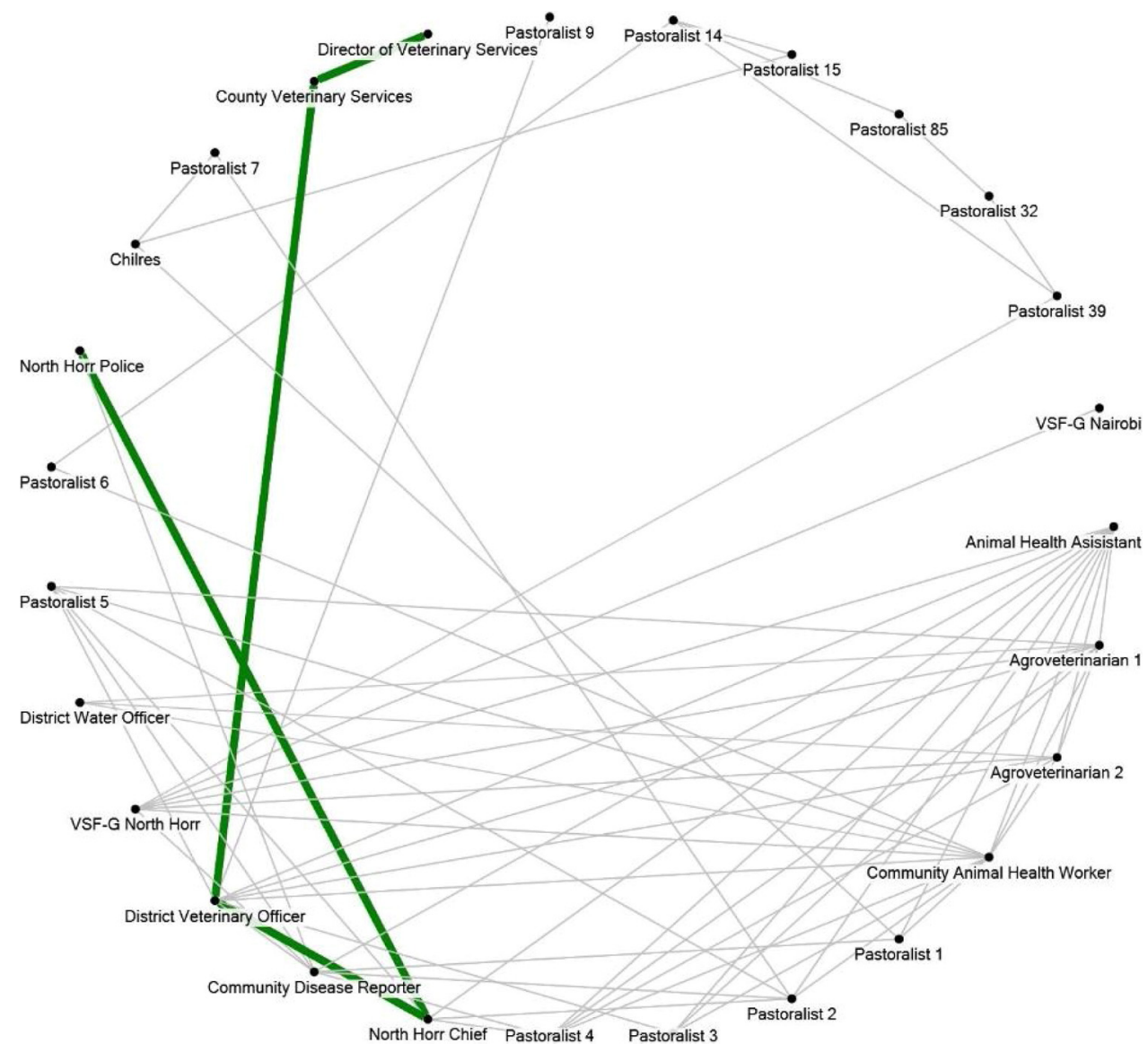

Fig. 5. Political pathway.

'unqualified' para-professionals, AVs were located within wide networks of animal health contacts but were perceived by herders as less able to leverage resources from government livestock services than CAHWs despite the CAHWs 'unofficial' status.

Exchanges between herders and CAHWs or AVs commonly fell into two categories; either herders suggested treatments and looked for confirmation by the AV/CAHW, or the herder approached AVs/CAHWs with symptoms and sought diagnostic and/or treatment decisions. The type of exchange depended on the herder's experience using other (typically traditional) pathways to get a diagnosis and treatment, the perceived ability of the CAHW/AV, and the resources available to both actors. The learning and development captured through the consultation with the CAHW or AV was typically fed back into wider community knowledge stocks through experiential sharing of outcomes. The use of Oxytetracycline ('Oxytet') to treat respiratory infections provides a useful example of this dynamic. Oxytet was widely stocked by CAHW and AVs for a range of conditions; it became so ubiquitous that herders would often asked for the compound by the manufacturer's name without providing symptoms or disease history. If, or when, Oxytet failed to resolve the condition, advice was sought from fellow herders and CAHW or AVs for alternatives and the results of new treatments discussed through community channels.

\subsection{Political pathway}

The political pathway was the smallest of the four identified in the study, with 5 actors connected by 8 relationships. The pathway was identified using the same methods as the other three through reporting transfer of livestock health knowledge, yet the content and character of the exchanges was markedly different. Rather than the disease reporting of the PDS network, the discursive exploration of the traditional, or interventions of the local, the political pathway was identified through attempts to deploy the power and influence of others to leverage resources related to animal health. For example several herders' suggested that as well as seeking PDS and traditional advice, they reported disease outbreaks to members of the local political establishment. This reporting was driven by a desire to maximise the chances that local DVOs would address their problems, linked to the feeling that sometimes engaging with formal government livestock health structures was of little direct benefit, "we do what we must, what we need. VSF can be good and can help when they have the programme or medicines that you need. Sometimes people in the manyatta (settlement) will have useful things, helpful things. But when you need important things or laboratories then you must have the DVO. And he is busy, very busy, and he only can see the big things that people show him. So if you know a man who can tell the DVO that your animals are sick, that is a big thing. Then, maybe, he will come" (North Horr Chief). The majority of actors in the political pathway held positions that enabled them to (formally or informally) act on the behalf of others. Access to these individuals was through possessing the necessary social capital or kinship networks, or in return for promises of political support. In many cases the local political actors actually had limited abilities to influence activities outside of their direct control - for example laboratory testing in Nairobi - but this was understood by local applicants to be part of wider negotiations.

\section{Discussion}

Closer exploration of animal health knowledge exchanges within and around the VSF-led PDS programme in North Horr provide insight into how pathways can overlap and intersect. The three core research questions proposed at the beginning of this article are considered below. 


\subsection{Which pathways of livestock disease knowledge exist within the community?}

The knowledge pathway maps provide a landscape view of the interconnectedness of the actors in the study. These interlacing structures show the majority of actors to have access to multiple relationships through which to share livestock health knowledge of which the PDS programme is one option amongst a suite of others. By exploring the character of exchanges the study identified four typologies of knowledge shared which enabled the mapping of pathways: a PDS, traditional, local, and political pathway. The PDS network linked NGO, government, and a limited selection of community actors through a non-indigenous formalised network of relationships. The traditional and local networks influenced by existing cultural (traditional subnetwork) and economic (local network) structures. The fourth pathway included more political exchanges; respondents who cited this network suggested the importance of using relationships to access state resources and favour.

The intersection of the four pathways echo findings from network studies on multiplexity (Hanneman and Riddle, 2005) that suggest how single relationships may have multiple dimensions such as status, perceptions, and trust, and how these dimensions are capable of interacting. Considering multiplex (as opposed to single-feature simplex relationships) can "provide a more realistic and more detailed picture of social reality and in turn deepens the understanding of the network under scrutiny" (Diviák et al., 2019, p.4). For logistical reasons this study focused on exchanges of livestock health knowledge, but the influence of unmapped connections cannot be discounted. Each actor will have had a myriad of parallel relationships including gender, family, economic, and wider cultural interactions. It is beyond the scope of this study to account for the influence of each of these, but it is vital to acknowledge their potential for shaping individual exchange pathways and eventual choices to participate in PE programmes.

\subsection{What knowledge is being transferred within these pathways?}

The four typologies above were identified using qualitative interview data. These data illustrate how discussions around livestock health are complex and dynamic, with actors reinforcing or challenging existing social structures and relations as part of the exchanges. For example many of the NGO actors interviewed were aware of herders discussing livestock diseases amongst themselves, but there was a tacit assumption that the PDS programme would be seen as 'high value' by indigenous livestock keepers by providing access to previously unobtainable resources and knowledge. This study suggests two ways in which this position may be incorrect. Firstly, the political pathway provides an example of how herders exploit power relationships to gain access to diverse resources. This highlights the role that individual perceptions and choices can play in the transfer of knowledge, often sidestepping formal cultural or state-led channels to achieve specific ends.

Secondly the transfer of knowledge is itself a powerful and political act that can serve to build, reinforce, or nullify relationships. Investing social and cultural capital in indigenous networks can reaffirm actors' positions within the community and secure ongoing access to social and cultural resources (Anbacha and Kjosavik, 2018) - advantages not provided by programmes such as the PDS. In these circumstances individuals who are less reliant upon indigenous social networks may be more inclined to engage with participatory programming. Work with East African pastoralist communities such as the Maasai (Thompson and Homewood, 2002) and Borana (Coppock et al., 2018) suggests elites are most able to exercise this ability - precisely those sections of the community commonly identified as unsuitable by critics of participatory development.

\subsection{What shapes actors' decisions to use a pathway?}

Bringing together interview and pathway data it is clear that multiple drivers influenced actors' choices to share knowledge. For some it was a matter of a waged, social, or cultural role; for the AHA, CDR, and DVO knowledge sharing was a duty. Many discussions between CAHWs, $\mathrm{AVs}$, Chilres, and herders mirrored many of these patterns of role reinforcement and positioning, legitimising knowledge and interests. It was evident that the to-and-fro exchanges of the traditional pathway were necessary to secure membership of a wider Gabra community, buying access as much as solving livestock health problems. In the language of multiplexity, participation in cultural structures and group discussions can be seen as an investment in a wider set of resources than animal health. Similarly exchanges between AVs and customers were spaces in which professionalisation and legitimisation could be established with vendors pushed to retain, rather than widely distribute livestock health knowledge as their livelihoods were dependent upon their role as holders of unique knowledge and resources.

Taken as a whole these findings demonstrate the diversity and complexity of livestock health knowledge and networks within the Gabra. Wider network literature suggests that key individuals, collectives, and technologies can drive the evolution of both knowledge and connections, and observation substantiated by this empirical data. For example, in this study the traditional pathway highlighted how East African democratic elder-councils may fulfil this role by reworking relationships. Drawing on participatory literature it is possible to suggest that development actors may overlook existing connections and believe they are creating new networks; this study suggests it may be closer to the truth to see PE not as discrete structures but as new threads sewn into broad tapestries. These fabrics contain overlapping, intersecting, and evolving relationships shaped in ways far removed from commonly apolitical discussions on participation. Considering the nuance of power and networks in PE, programming becomes even more important as connectivity between marginalised communities and the wider world increases through infrastructural and technological change. Transhumant and nomadic communities such as the Gabra are adapting and creating technological solutions that drive new forms of cultural exchanges, that in turn reshape Gabra culture itself through co-production (Jasanoff, 2004). Platforms such as WhatsApp and Telegraph place community voices into wider webs of resources, knowledge, and power, which may remain hidden to development groups - further complicating orthodox understandings of PE.

If participatory projects wish to shift from researcher-and-researched to a more equitable partnership development groups must pay closer attention to the multiple and asymmetric power relationships within communities. This study suggests that social science can help shed light on the complex landscapes of power and relationships to move PE forward. Framed by Fischer and Chenais (2019) differentiation of Participatory versus Local Epidemiology, this study suggests that social science can provide an understanding of local knowledge systems that may help shift projects towards more genuinely participatory forms of epidemiology.

\section{Conclusion}

This paper demonstrates the utility of including social science methodologies to understand how participatory programmes operate in complex, real-world environments. Qualitative enquiry uncovered how the PDS programme existed as one knowledge network amongst a complex constellation of local connections. The study identified how indigenous relationships and power asymmetries were capable of shaping exchanges around livestock health, enabling actors to draw on different resources that may be complementary or detrimental to the aims of the PDS programme. It is vital that development practitioners are capable of reflecting on the planning and practice of PE to recognise how indigenous networks and power both shape, and are shaped by, 
participatory projects, giving rise to persistent challenges that often dog participatory interventions.

\section{Ethical approval}

This study was approved through the University of Sussex ethic review panel application number ER/AT392/1 and written consent collected from all recipients; many respondents explicitly reserved their right to anonymity.

\section{Availability of data and materials}

The data that supports the findings is available on request from the author; this data is not publicly available due to its derivation from a wider study that includes relationship information that could identify respondents and compromise the privacy of research participants.

\section{Funding}

The study was funded under the UK Economic and Social Research Council grant number ES/J500173/1.

\section{Acknowledgements}

The author gratefully wishes to acknowledge the respondents who gave their time in this study. Particular thanks is due to the interpreters Abdoub, Yarra, Solomon, and Martha who offered invaluable interpretive insights alongside their data collection and translation contributions.

\section{Appendix A. Respondent list}

\begin{tabular}{|c|c|c|c|c|c|}
\hline Code & Label & Ethnicity & Primary Livelihood & Gender & Follow-up Interview? \\
\hline AHA & Animal Health Asisistant & Gabra & Technical & M & $\mathrm{Y}$ \\
\hline AV1 & Agroveterinarian 1 & Gabra & Technical & M & $\mathrm{Y}$ \\
\hline AV2 & Agroveterinarian 2 & Gabra & Technical & M & $\mathrm{Y}$ \\
\hline CAHW & Community Animal Health Worker & Gabra & Technical & M & $\mathrm{Y}$ \\
\hline CDR & Community Disease Reporter & Gabra & NGO & M & $\mathrm{Y}$ \\
\hline CHILR & Chilres & Gabra & Herder & M & $\mathrm{Y}$ \\
\hline CVS & County Veterinary Services & Non-Gabra & Government & M & $\mathrm{N}$ \\
\hline DVO & District Veterinary Officer & Non-Gabra & Government & M & $\mathrm{Y}$ \\
\hline DVS & Director of Veterinary Services & Non-Gabra & Government & M & $\mathrm{Y}$ \\
\hline DWO & District Water Officer & Non-Gabra & Government & M & $\mathrm{N}$ \\
\hline FP02 & Pastoralist 14 & Gabra & Herder & $\mathrm{F}$ & $\mathrm{Y}$ \\
\hline FP08 & Pastoralist 15 & Gabra & Herder & $\mathrm{F}$ & $\mathrm{N}$ \\
\hline $\mathrm{H} 1$ & Pastoralist 1 & Gabra & Herder & M & $\mathrm{N}$ \\
\hline $\mathrm{H} 2$ & Pastoralist 2 & Gabra & Herder & M & $\mathrm{N}$ \\
\hline H3 & Pastoralist 6 & Gabra & Herder & M & $\mathrm{N}$ \\
\hline $\mathrm{H} 4$ & Pastoralist 3 & Gabra & Herder & M & $\mathrm{N}$ \\
\hline H5 & Pastoralist 7 & Gabra & Herder & M & $\mathrm{Y}$ \\
\hline H6 & Pastoralist 4 & Gabra & Herder & M & $\mathrm{Y}$ \\
\hline H7 & Pastoralist 5 & Gabra & Herder & M & $\mathrm{N}$ \\
\hline MEP01 & Pastoralist 85 & Gabra & Herder & M & $\mathrm{Y}$ \\
\hline MP03 & Pastoralist 32 & Gabra & Herder & M & $\mathrm{N}$ \\
\hline MP11 & Pastoralist 9 & Gabra & Herder & M & $\mathrm{N}$ \\
\hline MP12 & Pastoralist 39 & Gabra & Herder & M & $\mathrm{N}$ \\
\hline $\mathrm{NHCH}$ & North Horr Chief & Gabra & Government & M & $\mathrm{Y}$ \\
\hline NHPOL & North Horr Police & Gabra & Government & M & $\mathrm{N}$ \\
\hline VSFNB & VSF-G Nairobi & Non-Gabra & NGO & M & $\mathrm{Y}$ \\
\hline VSFNH & VSF-G North Horr & Non-Gabra & NGO & M & $\mathrm{Y}$ \\
\hline
\end{tabular}

\section{Appendix B. Supplementary data}

Supplementary material related to this article can be found, in the online version, at doi:https://doi.org/10.1016/j.prevetmed.2020.105058.

\section{References}

Abler, R.F., 1974. The Geography of Communications. Transportation Geography: Comments and Readings. pp. 327-345.

Admassu, B., 2002. Primary animal healthcare in Ethiopia: the experience so far. In: Sones, K., Catley, A. (Eds.), Primary Animal Healthcare in the 21st Century: Shaping the Rules, Policies and Institutions, Mombasa, Kenya, pp. 38-39.

Alcoff, L.M., 1991. The problem of speaking for others. Cult. Crit. 20, 5-32.

Allepuz, A., de Balogh, K., Aguanno, R., Heilmann, M., Beltran-Alcrudo, D., 2017. Review of participatory epidemiology practices in animal health (1980-2015) and future practice directions. PLoS One 12, e0169198.

Allport, R., Mosha, R., Bahari, M., Swai, E., Catley, A., 2005. The use of community-based animal health workers to strengthen disease surveillance systems in Tanzania. Revue Scientifique et Technique-Office international des épizooties 24, 921.

ALRMP, I.I., 2008. Marsabit District Annual Progress Report for the July 2007-June 2008 period. Marsabit District Annual Progress Reports. Government of Kenya, Nairobi, Kenya.

Ameri, A., Hendrickx, S.C., Jones, B., Mariner, J.C., Mehta-Bhatt, P., Pissang, C., 2009. Introduction to Participatory Epidemiology and Its Application to Highly Pathogenic Avian Influenza Participatory Disease Surveillance: a Manual for Participatory Disease Surveillance Practitioners.
Anbacha, A.E., Kjosavik, D.J., 2018. Borana women's indigenous social network-marro in building household food security: case study from Ethiopia. Pastoralism 8, 29. Anderson, D.M., Broch-Due, V., 1999. The poor are not us: poverty and pastoralism, eastern african studies. James Currey Oxford, UK.

Arnstein, S.R., 1969. A ladder of citizen participation. J. Am. Inst. Plann. 35, 216-224.

Attride-Stirling, J., 2001. Thematic Networks: an analytic tool for qualitative research. Qual. Res. 1, 385-405.

Back, L., Solomos, J., 1993. Doing research, writing politics: the dilemmas of political intervention in research on racism: doing research, writing politics. Econ. Soc. 22, $178-199$.

Barker, D.C., 2005. Values, frames, and persuasion in presidential nomination campaigns. Polit. Behav. 27, 375-394.

Bastian, M., Heymann, S., Jacomy, M., 2009. Gephi: an open source software for exploring and manipulating networks. International AAAI Conference on Weblogs and Social Media 361-362.

Baxter, P.T.W., 1991. In: Baxter, P.T.W. (Ed.), When the Grass Is Gone: Development Intervention in African Arid Lands. The Scandinavian Institute of African Studies, Uppsala, ST.

Bellotti, E., 2016. Qualitative methods and visualizations in the study of friendship networks. Sociol. Res. Online 21, 1-19.

Birbili, M., 2000. Translating from one language to another. Social research update $31,1-7$. 
Castells, M., 2011. Network theory| A network theory of power. Int. J. Commun. 5, 15.

Catley, A., Leyland, T., 2001. Community participation and the delivery of veterinary services in Africa. Prev. Vet. Med. 49, 95-113.

Catley, A., Alders, R.G., Wood, J.L., 2012. Participatory Epidemiology: approaches, methods, experiences. Vet. J. 191, 151-160.

Cleaver, F., 1999. Paradoxes of participation: questioning participatory approaches to development. J. Int. Dev. 11, 597-612.

Cooke, B., Kothari, U., 2001. Participation: the New Tyranny? Zed Books, London, UK.

Coppock, D.L., Bailey, D., Ibrahim, M., Tezera, S., 2018. Diversified investments of wealthy Ethiopian pastoralists include livestock and urban assets that better manage risk. Rangel. Ecol. Manag. 71, 138-148.

Corbridge, S., Kumar, S., 2002. Programmed to fail? J. Dev. Stud. 39, 73-104.

Cronk, L., Berbesque, C., Conte, T., Gervais, M., Iyer, P., McCarthy, B., Sonkoi, D., Townsend, C., Aktipis, A., 2019. Managing Risk Through Cooperation: Need-based Transfers and Risk Pooling Among the Societies of the Human Generosity Project. Global Perspectives on Long Term Community Resource Management. Springer, pp. 41-75.

Dabasso, B.H., Okomoli, M.O., 2015. Changing pattern of local rainfall: analysis of a 50-year record in central Marsabit, northern Kenya. Weather 70, 285-289.

de Haan, C., Bekure, S., 1991. Animal Health Services in Sub-saharan Africa: Initial Experiences With Alternative Approaches. The World Bank.

Diocese of Marsabit, 2012. Personal Comment.

Diviák, T., Dijkstra, J.K., Snijders, T.A., 2019. Structure, multiplexity, and centrality in a corruption network: the Czech Rath affair. Trends Organ. Crime 22, 274-297.

Druckman, J.N., 2001a. The implications of framing effects for citizen competence. Polit. Behav. 23, 225-256.

Druckman, J.N., 2001b. On the limits of framing effects: Who can frame? J. Polit. 63, 1041-1066.

Edwards, R., 1998. A critical examination of the use of interpreters in the qualitative research process. J. Ethn. Migr. Stud. 24, 197-208.

Fischer, K., Chenais, E., 2019. What's in a name: participatory epidemiology. Prev. Vet. Med. 165, 34.

Fratkin, E., Roth, E.A., 2005. As Pastoralists Settle: Social, Health, and Economic Consequences of the Pastoral Sedentarization in Marsabit District, Kenya. Springer, New York.

Gamson, W.A., Modigliani, A., 1987. The changing culture of affirmative action. In: Braungart, R. (Ed.), Research in Political Sociology. Jai Press, Greenwich, CT, pp. 137-177.

Ganya, F.C., Haro, G.O., Borrini-Feyerabend, G., 2004. Conservation of dryland biodiversity by mobile indigenous people - the case of the gabbra of Northern Kenya. Policy Matters 13, 61-71.

Granovetter, M., 1983. The strength of weak ties: a network theory revisited. Sociol. Theory 1, 201-233.

Hadrill, D., 1989. In: Carr, M. (Ed.), Vets in Nepal and India: The Provision of Barefoot Animal Health Services. The Barefoot Book: Economically Appropriate Services for the Rural Poor. Intermediate Technology Publications, London, pp. 13-19.

Hanneman, R.A., Riddle, M., 2005. Introduction to Social Network Methods. University of California Riverside, Riverside, CA.

Hersberger, J., 2003. A qualitative approach to examining information transfer via social networks among homeless populations. New Rev. Inf. Behav. Res. 4, 95-108.

Herz, A., Peters, L., Truschkat, I., 2014. How to do qualitative structural analysis: the qualitative interpretation of network maps and narrative interviews. Forum Qualitative Sozialforschung/Forum: Qualitative Social Research.

Hillis, K., 1998. On the margins: the invisibility of communications in geography. Prog. Hum. Geogr. 22, 543-566.

Hogg, R., 1987. Settlement, pastoralism and the commons: the ideology and practice of irrigation development in Northern Kenya. In: Anderson, D., Grove, A.T. (Eds.), Conservation in Africa: People, Policies and Practice. Cambridge University Press, Cambridge, UK, pp. 293-306.

Holden, S., 1997. Community-based Animal Health Workers in Kenya: an Example of Private Delivery of Animal Health Services to Small-Scale Farmers in Marginal Areas. DFID Policy Research Programme R6120CA. DFID, London.

Jasanoff, S., 2004. The idiom of co-production. In: Jasanoff, S. (Ed.), States of Knowledge: The Co-Production of Science and Social Order. Routledge, London, UK, pp. 1-12.

Kimondiu, S.M., Duehnen, W., Buono, N., 2016. Participatory Epidemiology: Approaches, Methods, Experiences. Veterinaires Sans Frontieres Germany (VSF-G), Nairobi, Kenya.

Kolleck, N., 2013. How Corporations Wield Their Power: the Discursive Shaping of Sustainable Development. Handbook of Global Companies, pp. 143-152.

Kolleck, N., Bormann, I., 2014. Analyzing trust in innovation networks: combining quantitative and qualitative techniques of Social Network Analysis. Z. Fã $11 / 4 \mathrm{r}$ Erzieh. $17,9-27$.

Koppenjan, J.F.M., Koppenjan, J., Klijn, E.-H., 2004. Managing Uncertainties in Networks: a Network Approach to Problem Solving and Decision Making. Psychology Press.

Levy, D.L., Egan, D., 1998. Capital contests: national and transnational channels of corporate influence on the climate change negotiations. Polit. Soc. 26, 337-361.

Leyland, T., 1992. Participatory rural appraisal in Afghanistan. In: Livestock Services for Smallholders. Proceedings of an International Seminar Held in Yogyakarta, Indonesia. pp. 15-21.

Leyland, T., 1996. The World Without Rinderpest Outreach to the Inaccessible Areas: the Case for a Community-based Approach, With Reference to Southern Sudan. FAO Animal Production and Health Paper (FAO).

Little, P.D., Smith, K., Cellarius, B.A., Coppock, D.L., Barrett, C., 2001. Avoiding disaster: diversification and risk management among East African herders. Dev. Change 32, 401-433.

Lukes, S., 2012. Power: a radical view [2005]. Contemporary Sociological Theory 266.

Mansuri, G., Rao, V., 2004. Community-based and-driven development: a critical review. World Bank Res. Obs. 19, 1-39.

Maranga, S., 1992. Participatory information collection in Kenya and Zimbabwe. In: Livestock Services for Smallholders. Proceedings of an International Seminar Held in Yogyakarta, Indonesia. pp. 15-21.

Mariner, J., Hendrickx, S., Pfeiffer, D., Costard, S., Knopf, L., Okuthe, S., Chibeu, D., Parmley, J., Musenero, M., Pisang, C., 2011. Integration of participatory approaches into surveillance systems. Revue Scientifique et Technique: Office International des Epizooties 30, 653-659.

Mathias-Mundy, E., McCorkle, C.M., 1989. Ethnoveterinary Medicine: an Annotated Bibliography. Iowa State University Research Foundation Ames, US).

McFadyen, M.A., Cannella, A.A.J., 2004. Social capital and knowledge creation: diminishing returns of the number and strength of exchange. Acad. Manag. J. 47, 735-746.

Meusburger, P., Freytag, T., Suarsana, L., 2016. Ethnic and Cultural Dimensions of Knowledge. Springer, New York.

Mohan, G., Stokke, K., 2000. Participatory development and empowerment: the dangers of localism. Third World Q. 21, 247-268.

Mosse, D., 2001. 'People's knowledge', participation and patronage: operations and representations in rural development. In: Cooke, B., Kothari, U. (Eds.), Participation : The New Tyranny. Zed Books, London, UK.

Mugunieri, G., Irungu, P., Omiti, J., 2004. Performance of community-based animal health workers in the delivery of livestock health services. Trop. Anim. Health Prod. 36, 523-535.

Muriungi, K., 2012. Factors Affecting the Performance of Non-governmental Organizations' Projects in Kenya: a Case of Marsabit District.

Pretty, J.N., Guijt, I., Thompson, J., Scoones, I., 1995. A trainer's guide for participatory learning and action. IIED London, UK.

Robinson, L., 2002. Participatory rural appraisal: a brief introduction. Group Facilitation: A Research and Applications Journal 4, 45-52.

Robinson, L.W., Berkes, F., 2010. Applying resilience thinking to questions of policy for pastoralist systems: lessons from the gabra of Northern Kenya. Human Ecolology 38, 335-350.

Rosen, D., Lafontaine, P.R., Hendrickson, B., 2011. CouchSurfing: belonging and trust in a globally cooperative online social network. New Media Soc. 13, 981-998.

Sandford, S., 1983. Management of Pastoral Development in the Third World. Wiley, Chichester, UK.

Shen, F., Edwards, H.H., 2005. Economic individualism, humanitarianism, and welfare reform: a value-based account of framing effects. J. Commun. 55, 795-809.

Sikana, P., Bazeley, P., Kariuki, D., Fre, Z., 1992. The Kenya livestock and pastoral programme: some observations and reccomendations. ITDG, Nairobi.

Sligo, F., Massey, C., 2007. Risk, trust and knowledge networks in farmers' learning. J. Rural Stud. 23, 170-182.

Sligo, F., Massey, C., Lewis, K., 2005. Informational benefits via knowledge networks among farmers. J. Workplace Learn.

Smith, M., Milic-Frayling, N., Shneiderman, B., Mendes Rodrigues, E., Leskovec, J., Dunne, C., 2010. NodeXL: A Free and Open Network Overview, Discovery and Exploration Add-in for Excel 2007/2010/2013/2016, From the Social Media Research Foundation.

Stewart, J.M., Sinclair, A.J., 2007. Meaningful public participation in environmental assessment: perspectives from Canadian participants, proponents, and government. J. Environ. Assess. Policy Manag. 9, 161-183.

Tablino, P., 1999. The Gabra: Camel Nomads of Northern Kenya. Paulines Publications Africa Nairobi, Kenya.

Thompson, M., Homewood, K., 2002. Entrepreneurs, elites, and exclusion in Maasailand: trends in wildlife conservation and pastoralist development. Hum. Ecol. 30, 107-138.

Waller, R., Homewood, K., 2017. Elders and Experts: Contesting Veterinary Knowledge in a Pastoral Community. Western Medicine As Contested Knowledge. Manchester University Press.

Watson, D.J., Binsbergen, Jv., 2008. Livestock Market Access and Opportunities in Turkana. ILRI, Kenya.

Wilkinson, S., Kitzinger, C., 1996. Representing the Other: a Feminism \& Psychology Reader. Sage.

Witsenburg, K.M., Roba, A.W., 2004. Surviving Pastoral Decline: Pastoral Sedentarisation, Natural Resource Management and Livelihood Diversification in Marsabit District, Northern Kenya. Authors. 